Article

\title{
Comparison of Configurations for High-Recovery Inland Desalination Systems
}

\section{Tianyu Qiu and Philip A. Davies *}

Sustainable Environment Research Group, School of Engineering and Applied Science, Aston University, Birmingham B4 7ET, UK; E-Mail: qiut@aston.ac.uk

* Author to whom correspondence should be addressed; E-Mail: p.a.davies@aston.ac.uk; Tel.: +44-(0)121-204-3724; Fax: +44-(0)121-204-3683.

Received: 4 July 2012; in revised form: 11 August 2012 / Accepted: 10 September 2012 / Published: 17 September 2012

\begin{abstract}
Desalination of brackish groundwater (BW) is an effective approach to augment water supply, especially for inland regions that are far from seawater resources. Brackish water reverse osmosis (BWRO) desalination is still subject to intensive energy consumption compared to the theoretical minimum energy demand. Here, we review some of the BWRO plants with various system arrangements. We look at how to minimize energy demands, as these contribute considerably to the cost of desalinated water. Different configurations of BWRO system have been compared from the view point of normalized specific energy consumption (SEC). Analysis is made at theoretical limits. The SEC reduction of BWRO can be achieved by (i) increasing number of stages, (ii) using an energy recovery device (ERD), or (iii) operating the BWRO in batch mode or closed circuit mode. Application of more stages not only reduces SEC but also improves water recovery. However, this improvement is less pronounced when the number of stages exceeds four. Alternatively and more favourably, the BWRO system can be operated in Closed Circuit Desalination (CCD) mode and gives a comparative SEC to that of the 3 -stage system with a recovery ratio of $80 \%$. A further reduction of about $30 \%$ in SEC can be achieved through batch-RO operation. Moreover, the costly ERDs and booster pumps are avoided with both CCD and batch-RO, thus furthering the effectiveness of lowering the costs of these innovative approaches.
\end{abstract}

Keywords: desalination; reverse osmosis; brackish water; high recovery; system design 


\section{Introduction}

Water is vital for all living creatures on Earth. About $97 \%$ of the water is seawater in oceans, leaving only $2.5 \%$ of the water on the Earth as fresh water, and about $99 \%$ of that water is in ice and underground. Because of population growth, industrialization and climate change, water scarcity has become one of the most pervasive problems afflicting people throughout the world. Presently, over one-third of the world's population lacks access to safe drinking water and suffers the consequences of unacceptable sanitary conditions [1]. Alongside existing water conservation measures, salt water desalination by reverse osmosis (RO) membrane has been proved [2] to be a more proactive and dynamic way to water our 'blue' but thirsty world.

For many inland and arid areas that have adequate groundwater resources but are far from the sea, desalination of brackish groundwater (BW) is urgently needed to increase water supply, satisfy the purposes of drinking, irrigation, and industry use. And there has been a rapid growth in the installation of brackish water reverse osmosis (BWRO) desalination facilities in the past decade. Nations, spanning from Australia to Spain, from the United States to China, all have BWRO desalination projects accomplished, and construction of new plants is expected to increase in the near future. In Texas alone, by 2006, thirty BWRO desalination plants with design capacity more than $95 \mathrm{~m}^{3} / \mathrm{day}$ had been constructed [3]. The total desalination capacity of these facilities is around $132,400 \mathrm{~m}^{3} / \mathrm{day}$. The capital costs of these facilities vary from $0.02 \$ / \mathrm{m}^{3}$ to $2 \$ / \mathrm{m}^{3}$ according to the scale of the plants. Generally, desalination facilities at large scale have a lower capital cost.

However, the cost could be substantially increased because of brine management requirements. These plants produce a waste concentrate stream in the vicinity of $38,000-57,000 \mathrm{~m}^{3} /$ day. Almost $70 \%$ of the concentrate from these facilities was discharged to surface water body or municipal sewer, $20 \%$ was treated by evaporation pond, and around $10 \%$ was managed by land application. Since these plants are placed far from the coast, direct discharge of the brine will easily affect the surrounding ecosystem. Pérez-González et al. [4] gave a comprehensive review on the potential treatments of reject brine according to the source of RO concentrates and the maturity of the technologies. However, for the large amount of brine from desalination facilities in Texas, a proper treatment that can overcome the environmental problems associated with the direct discharge of RO brine increases costs considerable [5].

Besides brine management, another major challenge is the energy demand of inland BWRO systems, which is again linked to the cost of desalinated water. The energy demand of seawater RO desalination plants has decreased dramatically in the last 40 years [6], from about $10-15 \mathrm{kWh} / \mathrm{m}^{3}$ of produced water to $2-3 \mathrm{kWh} / \mathrm{m}^{3}$. This is attributed to the advance of membrane technology and the development of high efficiency energy recovery devices (ERDs). However, most of the current RO plants are still prone to energy intensity when it comes to the desalination of BW on small-scale, due to relatively smaller components, e.g., pumps, and absence of ERDs [7]. Therefore, improving the energy efficiency of BW desalination, increasing water output per land area, minimizing the discharged brine, and eventually reducing cost are of course some of the desirable properties when designing the BWRO system. To achieve these, there have been several approaches, including using highly permeable membrane materials [8,9], employing high efficiency ERD to recover the energy losses in pressurized brine, and using renewable energy resources to subsidize the electrical energy 
demand $[10,11]$. Optimum designs of BWRO systems [12,13] provide another effective approach to achieve these goals.

In this work, we discuss some of the critical design considerations and criteria for BWRO plants. A particular focus is put on the crucial design for pre-treatment processes with the emphasis on the effects of different configurations on the BWRO systems. Various pre-treatment approaches and their functionalities are comparatively reviewed. Some popular candidate processes with the optimal designs, such as single and multi-stage RO with/without ERD, are carefully investigated through theoretical analysis of their SEC. Innovative RO systems that operate in either batch mode or closed circuit mode are extensively compared with the more conventional designs. We further elucidate the advantages of these innovative systems in real-world applications.

\section{Pre-treatment of BWRO System}

Water can be categorized by its salinity level. Seawater has total dissolved solids (TDS) concentration of about $35,000 \mathrm{mg} / \mathrm{L}$ on average; BW usually has TDS concentration of $3000-10,000 \mathrm{mg} / \mathrm{L}$ and the TDS concentration of fresh water can be up to $1000 \mathrm{mg} / \mathrm{L}$. According to the guidelines for drinking water quality provided by the U.S. Environmental Protection Agency (EPA), water with salinity below $500 \mathrm{mg} / \mathrm{L}$ is acceptable for drinking [2]. Thus, it is essential to desalinate BW to produce drinking water. Brackish water composition varies widely among inland areas. Examples of BW compositions from different origins of the world are shown in Table 1. Unlike evaporative desalination plants, the site-specific BW composition has a direct influence on the RO plant design, e.g., pre-treatment design. Thus, a complete and accurate analysis of the water composition must be carried out before design begins. Despite the recent improvements in the performance of the fouling-resistant membranes [6], the RO membranes are still extremely sensitive to the fouling contaminants, which affect the energy usage, reliability, and environmental impact of the BWRO plant. Therefore, pre-treatments of feed BW are essential and sometimes critical [14].

\subsection{Pre-treatment Processes}

Typical site-specific parameters of the raw BW to be controlled before it enters RO modules include: water hardness, water turbidity, organic substances, water temperature and $\mathrm{PH}$. These feed water related parameters, together with the RO membrane material, RO module system, required recovery and permeate quality, decide the method and the degree of the necessary pre-treatment. Pre-treatment processes may consist of several conventional treatment steps as summarized in Table 2. Brackish surface water typically has a greater propensity for membrane fouling and requires more extensive pretreatment systems than groundwater resources. Different methods should be carefully selected in order to cause minimum membrane fouling at the lowest possible cost. And the amounts of chemicals added have to be precisely calculated depending on the scale forming salts contained in the feed water. For example, for water with low bacteria content, pre-treatment may only require addition of polyelectrolyte as flocculation agent, and $\mathrm{H}_{2} \mathrm{SO}_{4}$ to reduce the $\mathrm{pH}$ level and thus prevent $\mathrm{CaCO}_{3}$ precipitation. On the other hand, in the case of water with high bacteria content, more steps of chlorine addition and de-chlorination should be included before the final stage consisting of a cartridge filter. 
Utilization of microfiltration (MF), ultrafiltration (UF), or nanofiltration (NF) to pre-treat RO feed water, as effective substitute of conventional pre-treatment, has became a new trend. Pilot-scale testing of these membranes has been carried out by researchers. To date, UF membranes are the most common choice in research studies and pilot testing [15]. UF membranes have smaller pore sizes than MF membranes and can therefore achieve more effective removal. Further, UF membranes have higher flux than NF membranes, making it possible to treat feed water with relatively lower energy consumption [2]. All three membranes have advantageous characteristics, such as superior removal of organic and particulate matter. However, like the RO membranes, these pre-treatment membranes are easily fouled.

Table 1. Example of brackish water composition from different locations.

\begin{tabular}{|c|c|c|c|c|c|}
\hline Parameter & unit & $\begin{array}{c}\text { Palmas, Canary } \\
\text { Islands, Spain [16] }\end{array}$ & $\begin{array}{c}\text { Rewari, } \\
\text { India }\end{array}$ & $\begin{array}{l}\text { Benandarah New South } \\
\text { Wales, Australia }[17,18]\end{array}$ & $\begin{array}{c}\text { Dockum, Texas, } \\
\text { USA [5] }\end{array}$ \\
\hline Arsenic (As) & $\mathrm{mg} / \mathrm{L}$ & - & - & $<0.005$ & - \\
\hline Boron (B) & $\mathrm{mg} / \mathrm{L}$ & - & - & 0.21 & - \\
\hline Calcium $(\mathrm{Ca})$ & $\mathrm{mg} / \mathrm{L}$ & 124 & 84 & 142.1 & 263 \\
\hline Chloride $(\mathrm{Cl})$ & $\mathrm{mg} / \mathrm{L}$ & $1,009.6$ & 1,220 & 1,483 & 670 \\
\hline Fluoride (F) & $\mathrm{mg} / \mathrm{L}$ & 0.0 & 11.1 & $<0.1$ & - \\
\hline Iron $(\mathrm{Fe})$ & $\mathrm{mg} / \mathrm{L}$ & 0.0 & 0.03 & 28.87 & - \\
\hline Magnesium $(\mathrm{Mg})$ & $\mathrm{mg} / \mathrm{L}$ & 138.87 & 79 & 192 & 141 \\
\hline Manganese (Mn) & $\mathrm{mg} / \mathrm{L}$ & - & - & 0.5 & - \\
\hline Nitrate $\left(\mathrm{NO}^{3-}\right)$ & $\mathrm{mg} / \mathrm{L}$ & 416.3 & 0.69 & $<1.0$ & - \\
\hline Nitrite $\left(\mathrm{NO}^{2-}\right)$ & $\mathrm{mg} / \mathrm{L}$ & - & - & $<0.1$ & - \\
\hline Potassium (K) & $\mathrm{mg} / \mathrm{L}$ & 33.2 & - & 19.2 & - \\
\hline Sodium (Na) & $\mathrm{mg} / \mathrm{L}$ & 910.0 & 1,310 & 1,125 & 589 \\
\hline Sulphate $\left(\mathrm{SO}_{4}{ }^{2-}\right)$ & $\mathrm{mg} / \mathrm{L}$ & 569.1 & 1,172 & 340 & 1,329 \\
\hline $\mathrm{SiO}_{2}$ & $\mathrm{mg} / \mathrm{L}$ & 33 & - & - & 70 \\
\hline $\mathrm{HCO}_{3}^{-}$ & $\mathrm{mg} / \mathrm{L}$ & 677.9 & 976 & - & 227 \\
\hline $\begin{array}{l}\text { Total hardness } \\
\qquad\left(\mathrm{CaCO}_{3}\right)\end{array}$ & $\mathrm{mg} / \mathrm{L}$ & - & 534 & 1,146 & - \\
\hline $\mathrm{pH}$ & - & 7.7 & 7.3 & 6.7 & 7.4 \\
\hline TDS & $\mathrm{mg} / \mathrm{L}$ & 3,912 & 3,668 & 3,400 & 3,314 \\
\hline
\end{tabular}

Table 2. Pre-treatment Processes, summarized from references [19,20].

\begin{tabular}{|c|c|c|c|}
\hline \multicolumn{2}{|c|}{ Pre-treatment process } & Main functions & \multirow{2}{*}{$\begin{array}{c}\begin{array}{c}\text { Suitable water } \\
\text { resources }\end{array} \\
\text { Well water, } \\
\text { surface water }\end{array}$} \\
\hline \multirow{4}{*}{$\begin{array}{l}\text { Chemical } \\
\text { treatments }\end{array}$} & $\begin{array}{l}\text { Addition of } \\
\text { coagulants }\end{array}$ & $\begin{array}{l}\text { Act to flocculate colloidal dispersions, which is easy } \\
\text { to separate }\end{array}$ & \\
\hline & Acid addition & $\begin{array}{l}\text { To decrease the } \mathrm{pH} \text {, thus diminish the precipitation } \\
\text { propensity of alkaline scaling species such as } \mathrm{CaCO}_{3} \text { and } \\
\mathrm{Mg}(\mathrm{OH})_{2} \text {. Sulphuric acid is usually employed. }\end{array}$ & Surface water \\
\hline & $\begin{array}{l}\text { Addition of } \\
\text { anti-scalants }\end{array}$ & $\begin{array}{l}\text { To enable concentration of the feed water above the scale } \\
\text { precipitation limits, avoid membrane scaling }\end{array}$ & Surface water \\
\hline & $\begin{array}{l}\text { Addition of } \\
\text { sodium bisulfite } \\
\left(\mathrm{NaHSO}_{3}\right)\end{array}$ & $\begin{array}{l}\text { To reduce free chlorine, that can easily attack membrane due } \\
\text { to oxidants. The removal of excess chlorine can also be } \\
\text { achieved with activated carbon filter }\end{array}$ & Surface water \\
\hline
\end{tabular}


Table 2. Cont.

\begin{tabular}{|c|c|c|c|}
\hline \multicolumn{2}{|c|}{ Pre-treatment process } & Main functions & $\begin{array}{l}\text { Suitable water } \\
\text { resources }\end{array}$ \\
\hline \multirow{4}{*}{$\begin{array}{l}\text { Chemical } \\
\text { treatments }\end{array}$} & $\begin{array}{l}\text { Addition of } \\
\text { coagulants }\end{array}$ & $\begin{array}{l}\text { Act to flocculate colloidal dispersions, which is easy } \\
\text { to separate }\end{array}$ & $\begin{array}{l}\text { Well water, } \\
\text { surface water }\end{array}$ \\
\hline & Acid addition & $\begin{array}{l}\text { To decrease the } \mathrm{pH} \text {, thus diminish the precipitation } \\
\text { propensity of alkaline scaling species such as } \mathrm{CaCO}_{3} \\
\text { and } \mathrm{Mg}(\mathrm{OH})_{2} \text {. Sulphuric acid is usually employed. }\end{array}$ & Surface water \\
\hline & $\begin{array}{l}\text { Addition of anti- } \\
\text { scalants }\end{array}$ & $\begin{array}{l}\text { To enable concentration of the feed water above the } \\
\text { scale precipitation limits, avoid membrane scaling }\end{array}$ & Surface water \\
\hline & $\begin{array}{l}\text { Addition of } \\
\text { sodium bisulfite } \\
\left(\mathrm{NaHSO}_{3}\right)\end{array}$ & $\begin{array}{l}\text { To reduce free chlorine, that can easily attack membrane } \\
\text { due to oxidants. The removal of excess chlorine can also } \\
\text { be achieved with activated carbon filter }\end{array}$ & Surface water \\
\hline \multirow{4}{*}{ Filtration } & Mesh strainer & $\begin{array}{l}\text { To initially remove large particles, avoid membrane } \\
\text { blocking }\end{array}$ & $\begin{array}{l}\text { Well water, } \\
\text { surface water }\end{array}$ \\
\hline & Media filtration & $\begin{array}{l}\text { To remove particulate and suspended matter, avoid } \\
\text { membrane blocking, used commonly in conventional } \\
\text { desalination plant }\end{array}$ & Surface water \\
\hline & $\begin{array}{l}\text { Micron cartridge } \\
\text { filtration }\end{array}$ & $\begin{array}{l}\text { Universally used in front of the modules of any RO } \\
\text { plant, serve as the final barrier to water born particles. } \\
\text { The filter elements with a nominal pore size of about } 5 \\
\mu \mathrm{m}\end{array}$ & $\begin{array}{l}\text { Well water, } \\
\text { surface water }\end{array}$ \\
\hline & Filtration aids & $\begin{array}{l}\text { To increase the efficiency of filtration processes by } \\
\text { adding filtration aids, such as organic polymers }\end{array}$ & $\begin{array}{l}\text { Well water, } \\
\text { surface water }\end{array}$ \\
\hline \multicolumn{2}{|c|}{ Disinfection } & $\begin{array}{l}\text { Using disinfecting agents such as chlorine, organic } \\
\text { biocides, ozone and UV irradiation to control biological } \\
\text { activity, protect the membrane }\end{array}$ & $\begin{array}{l}\text { Well water, } \\
\text { surface water }\end{array}$ \\
\hline
\end{tabular}

\section{Conventional BWRO Plant}

Usually, BWRO desalination plants implement a basic configuration of one stage, as shown in Figure 1, and the membrane module may contains one or several RO elements in series. Taking the BWRO plant in Saja'a UAE as an example, the feed water of the plant is from a well water field with average TDS being $3261 \mathrm{mg} / \mathrm{L}$, and the RO feed pressure is maintained in the range of $18-20 \mathrm{bar}$. This plant is operated at a recovery of about $68 \%$ in order to meet the production need of $22,710 \mathrm{~m}^{3} /$ day. To increase the output, an additional seawater membrane RO unit was added to recover the high pressure brine [21]. By utilizing the seawater RO unit at a recovery fraction of $40 \%$, additional water output of $3027 \mathrm{~m}^{3} /$ day was achieved. Figure 2 illustrates the RO module arrangement with an additional membrane module. This configuration must be operated at a pressure well above the osmotic pressure of the feed water, to overcome the osmotic pressure reached at the exit of the second module. Thus, it is desired to use a RO module with low operation pressure, high permeate flux and high salt rejection as the second module. Nemeth [22] used a similar idea to improve the performance of a conventional BWRO plant. By utilizing a hybrid combination of ultra-low pressure and conventional membranes, the average flux was increased up to $10 \%$, and the permeate TDS decreased by around $20 \%$. The same author [22] also proposed an optimum design by incorporating inter-stage pressure boosting or 
utilizing permeates throttling at the first stage, and the flux through the second module was increased by $40 \%$ and $37 \%$, respectively.

Figure 1. Conventional one stage brackish water reverse osmosis (BWRO) system.

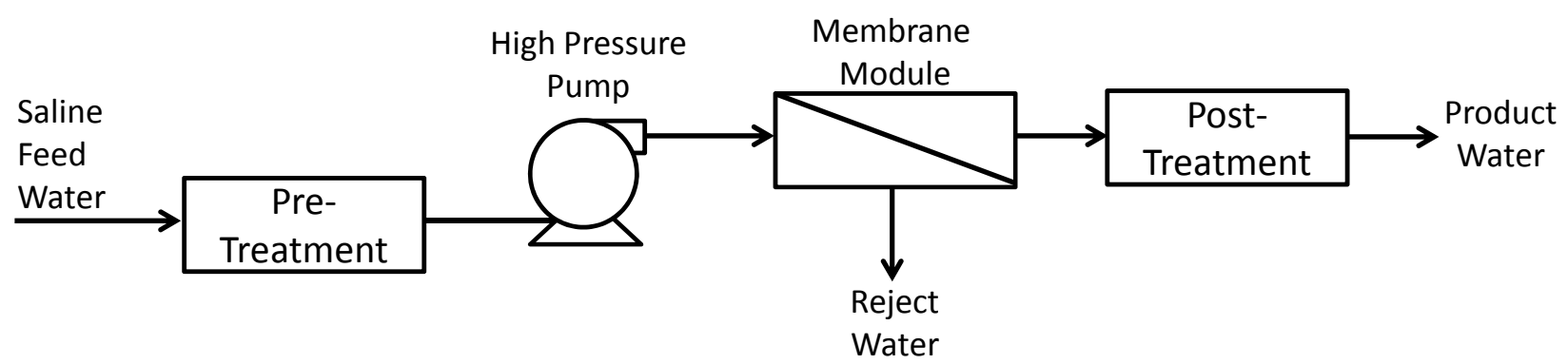

Figure 2. BWRO system with additional membrane module connected to the reject water.

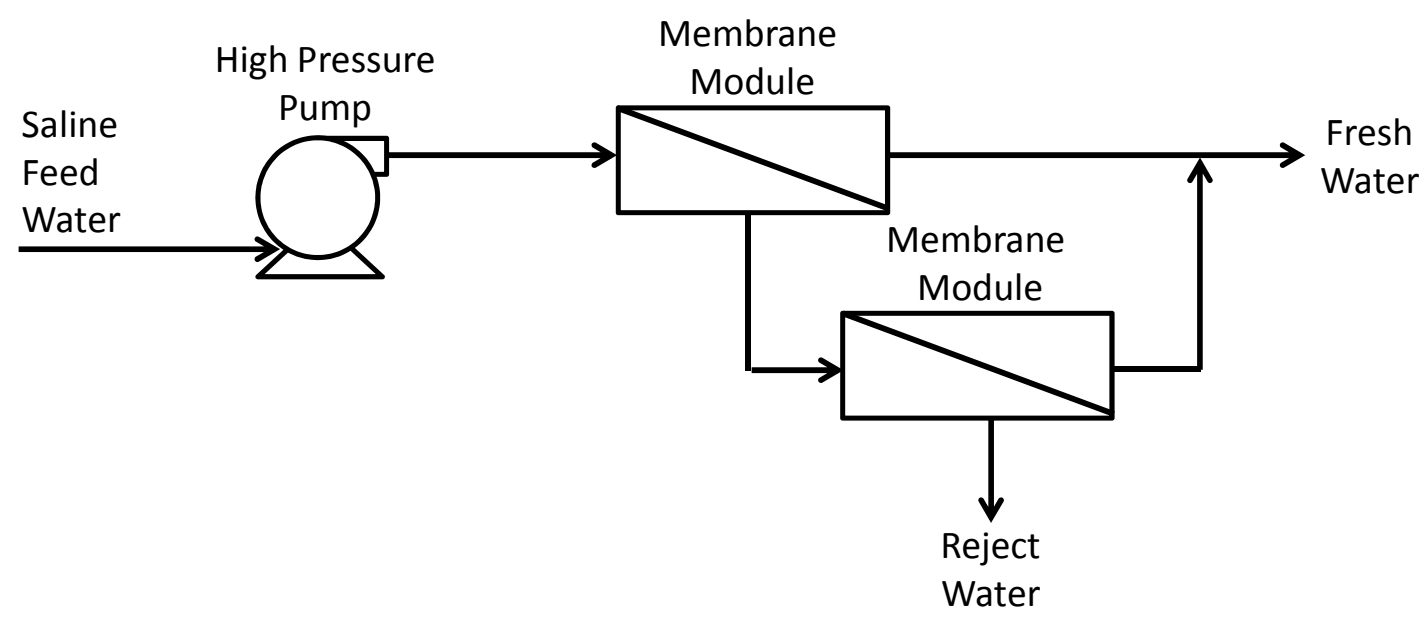

\section{Optimal Designs of Conventional BWRO System}

A BWRO desalination system can be modified in various ways to improve its performance. One common approach is to change the number of membrane elements in a module and the arrangement of the modules. Typically, the BWRO plant is arranged in a staged array; that is the subsequent stage contains half as many membrane modules as the previous one, i.e., 2:1 array. Nemeth has shown [22] that using a 3:1 array requires a slightly lower feed pressure, but lowers the concentrate flow in the first stage simultaneously. Other re-design approaches are also adopted. The development and implementation of optimized configurations have been seen to lead to a reduction in energy consumption of the RO desalination plants. Moreover, a BWRO system may be operated in a batch mode and without an ERD. To date, most of the small-scale RO systems were built without an ERD. It may keep capital costs down but come at the expense of a heavy penalty on energy costs. For BWRO systems, they usually have much higher recovery ratios; thus, energy recovery is less critical.

\subsection{Multi-stage Configuration}

For an RO system, a serial arrangement of the RO membrane elements is more energy efficient than a parallel one [23]. For serial arrangements, however, a substantial longitudinal gradient in concentration 
will occur. In desalination process, fresh water is progressively removed along the RO membrane module, the salt concentration along the channel increases to a value almost twice (for seawater) or three times (for BW) that at the inlet. To maintain a flux of water over the entire feed channel, the operation pressure is determined by the concentration at the outlet rather than the inlet, as illustrated in Figure 3a. Thus, part of the feed energy is lost due to the longitudinal concentration gradient.

One example of system design that can eliminate this loss is a multi-stage configuration. This design adopts several stages in series along with several booster pumps. The first stage operates at a lower pressure, because of the lower salinity of the feed water. The concentrate from the first stage is then fed into a second stage, where the salinity becomes higher. The inter-stage booster pump provides higher pressure correspondingly, thus removing the necessity to have the first-stage pump providing extra pressure. Consequently, the energy loss associated with the increased longitudinal concentration can be minimized. Figure $3 \mathrm{~b}$ gives a direct illustration of the energy savings achieved by the 3 -stage RO system with the three pumps providing pressure $P_{1}, P_{2}$ and $P_{3}$.

Figure 3. Energy usage of a reverse osmosis (RO) system and the effect of longitudinal concentration gradient. The theoretical minimum energy demand for desalination, which is represented by the area under the osmotic pressure curve, is equal to the energy needed to bring saline water to the maximum osmotic pressure in the corresponding module. (a) For single-stage system, the operation pressure $P$ must be at least equal to the osmotic pressure $\pi$ of the solution at the outlet of membrane module. The applied energy is represented by the area under the dashed line. The difference between these two areas (gray area) is the provided extra energy, i.e., energy loss. (b) For 3-stage system, by providing appropriate pressure for each stage, the energy loss (gray area) is reduced, and some of the extra energy is saved (pink area) — based on [6].

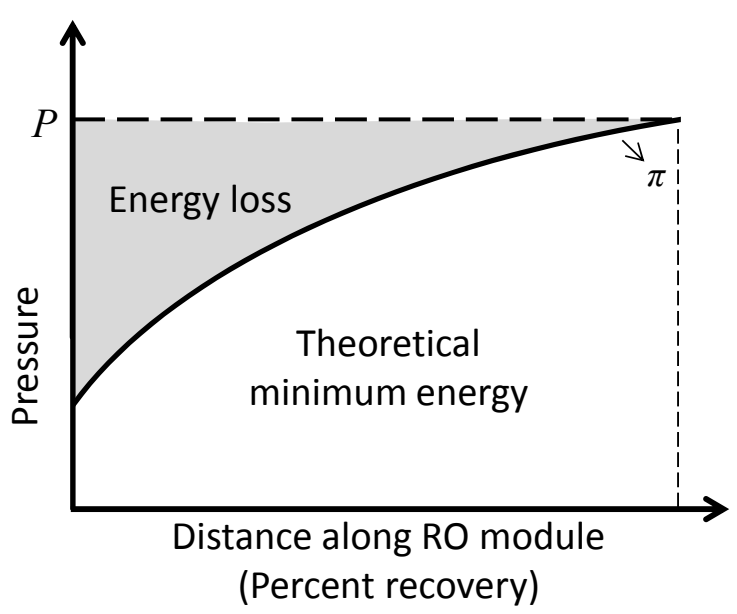

(a)

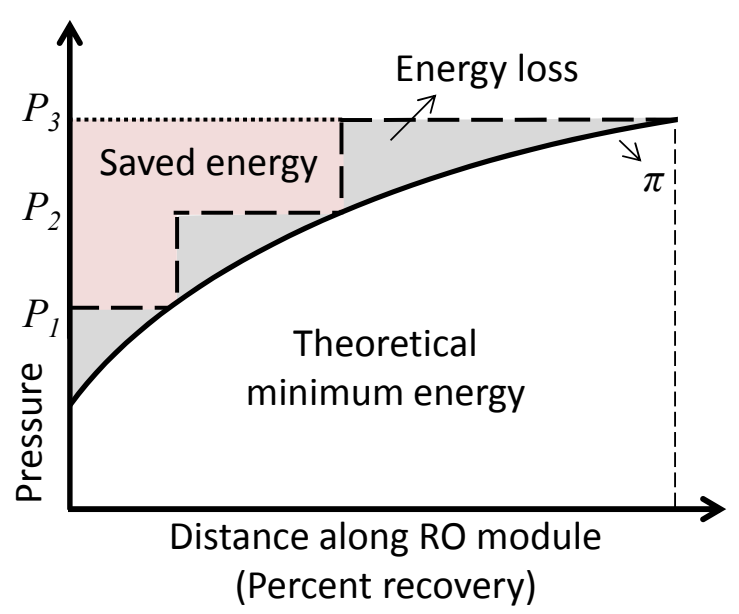

(b)

The configurations of single and multi-stage BWRO systems with or without an ERD are depicted in Figures 4-7. A Design study by Vince et al. [24] has shown that multi-stage systems, with modules connected to reject water with booster pumps, are able in principle to minimize the electricity consumption. Lu et al. [25] also recommended that for low feed concentration (around $3000 \mathrm{mg} / \mathrm{L}$ ), the optimal design is a 3-stage system with ERD that can increase recovery ratio. In 
practice, however, simple one-stage systems have often been favoured because of the lower capital cost - despite their relatively poor energy efficiency [18]. Thus, the choice of one- or multi-stage configuration needs careful attention.

Figure 4. Single-stage system.

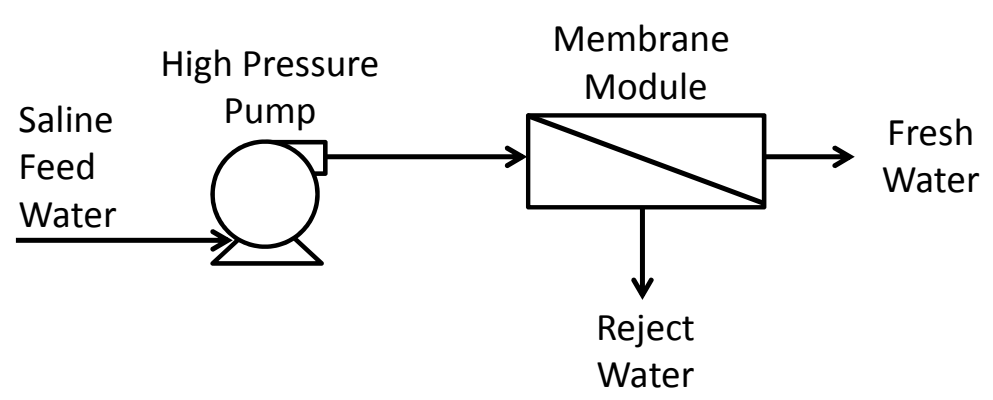

Figure 5. 3-stage system with intermediate pumps.

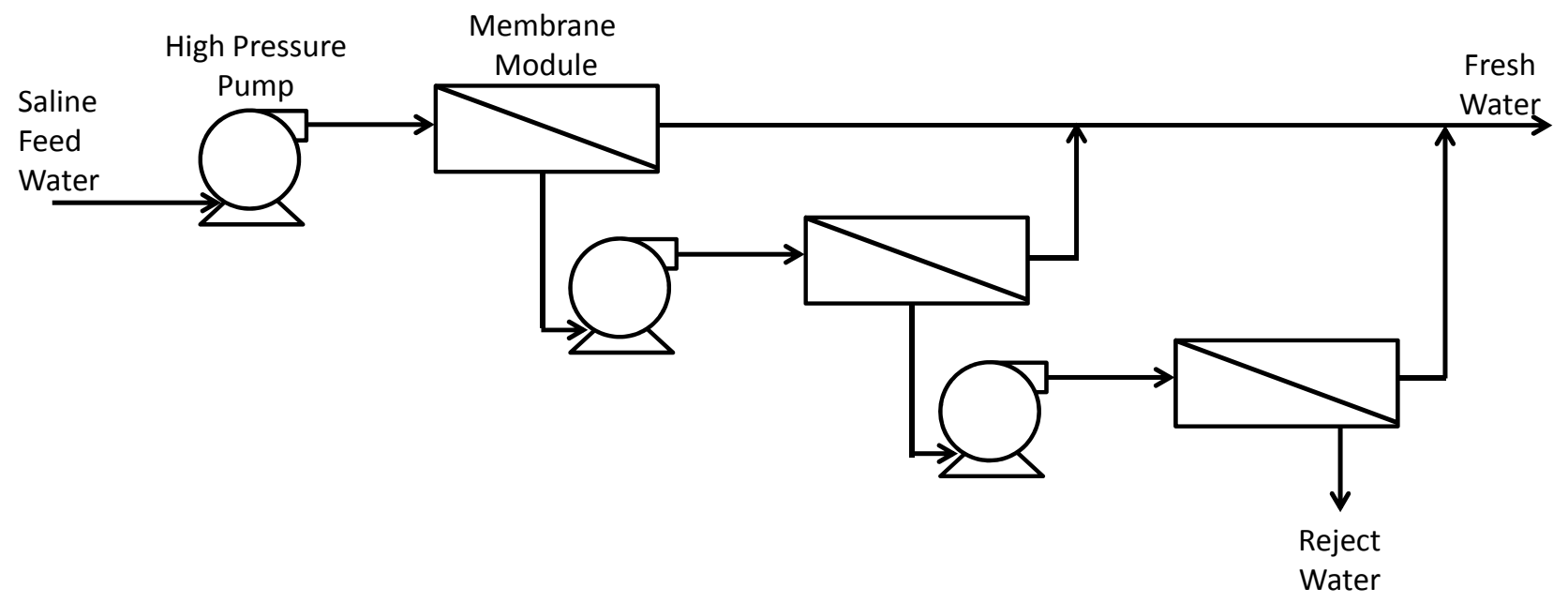

Figure 6. Single-stage system with work exchanger type energy recovery device (ERD).

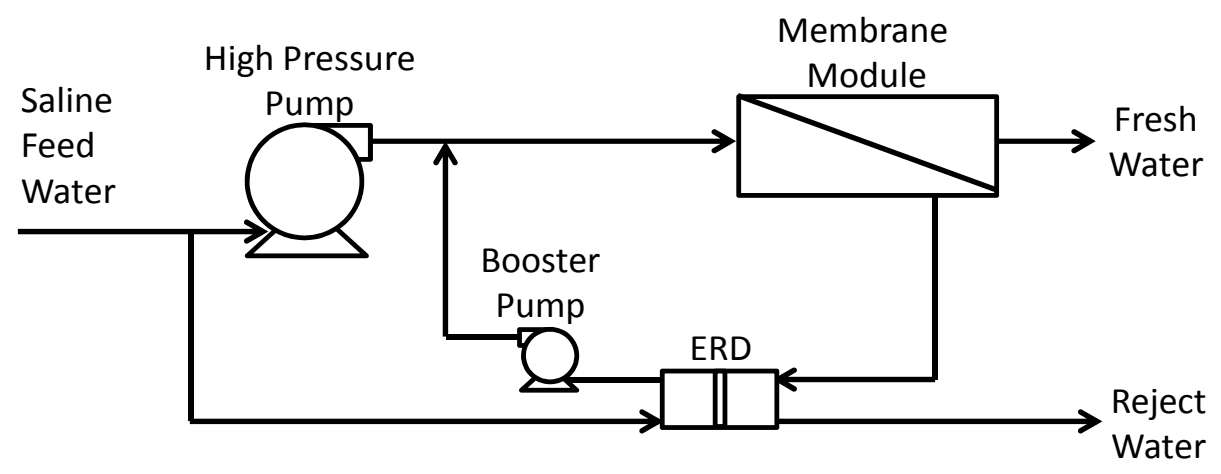


Figure 7. Multi-stages system with work exchanger type ERD.

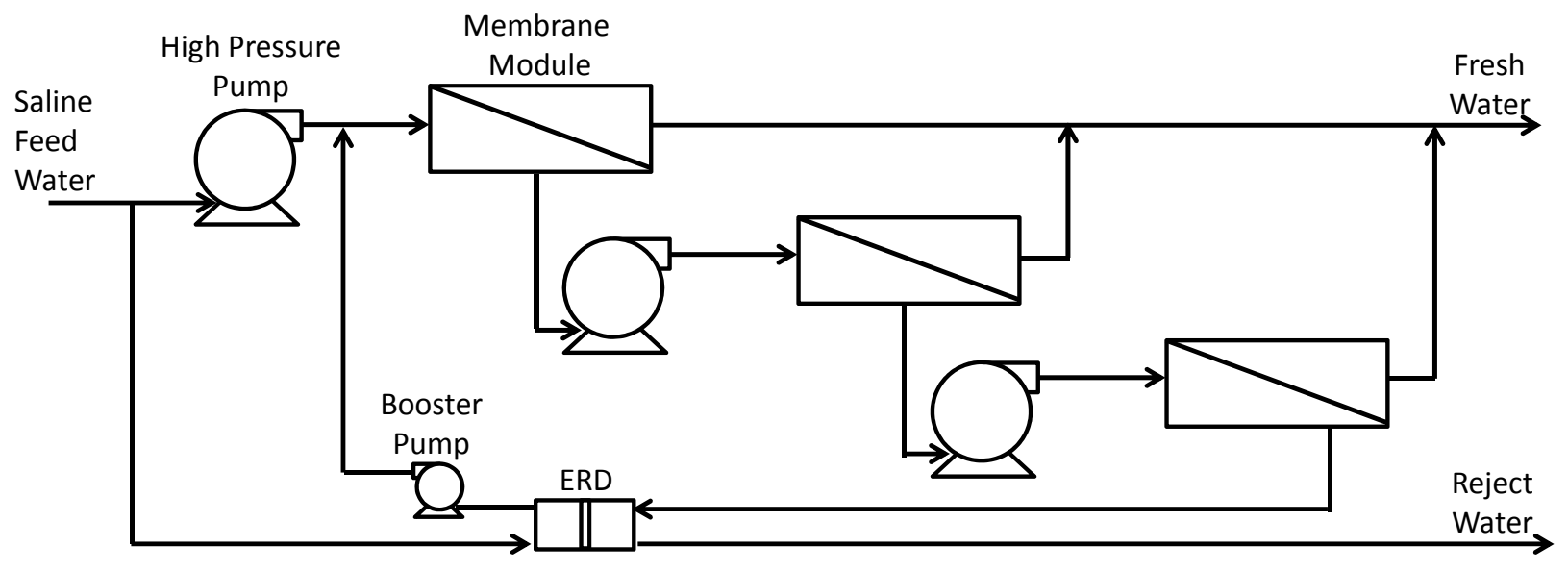

\section{Innovative Configurations Using Time-varying Conditions}

Multi-staging attempts to overcome the problem of longitudinal concentration gradient by spatial separation of the system into modules working at different pressures. A contrasting approach is temporal separation, whereby a single module is operated at time-varying pressure as the concentration and osmotic pressure gradually increase. (Note that these two approaches - separation in space or time-are recognizable from the methodology of TRIZ). An advantage of the time-varying (i.e., non-steady) approach is that it is possible in principle to attain the theoretical minimum energy of desalination; whereas with multi-staging, this would only be possible if an infinite number of stages were employed. Here we describe two distinct but related approaches using the time-varying approach.

\subsection{Batch Mode RO Operation}

Batch operations are common in traditional filter presses (e.g., for making wine). For RO, they are used in laboratory filtration cells for experimental purposes, but they have rarely been employed at process scale with a view to optimizing energy efficiency. The design philosophy of the batch mode operation is illustrated in Figure 8. Saline water is contained in a water cylinder. The cylinder piston driven by the input work pressurizes the saline water against the RO membrane and the permeate is expelled. To diminish the undesirable concentration polarization effects at the membrane surface, a stirring device is applied. A practical realization is shown in Figure 9 [12]. During the pressurization stage, the pressurized concentrate is fed back into the pump cylinder with the help of the re-circulation pump. Batch mode operation provides energy recovery, without the need for a separate ERD.

Davies [12] has presented a batch system-DesaLink - in which batch-RO can be powered by the work generated from steam expansions, which is interesting for incorporation into thermal and solar thermal plant allowing for a range of end purposes (i.e., co-generation). DesaLink comprises two subsystems, namely a power system and a batch-RO system. The pistons of these two subsystems are coupled by a crank mechanism to provide mechanical advantage during the desalination process. DesaLink works on the principle that the mechanical energy provided by the steam expansion is directly applied to the feed water without any further conversion steps; thus losses will be minimized. The aim is to produce high fresh water output but also reduce brine discharge with low energy 
consumption [26]. Detailed information about this system can be found elsewhere [12]. At the time of writing, DesaLink is still at the prototype stage of development.

Figure 8. The essence of the batch mode RO process.

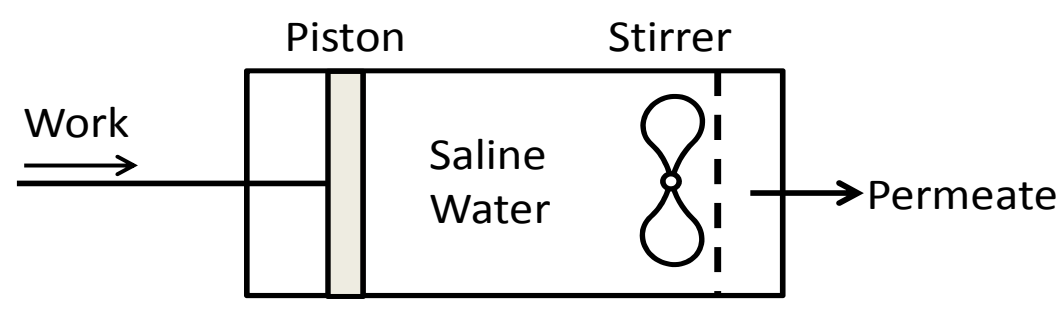

RO membrane

Figure 9. Three stages of the batch mode RO operation, from [27]. The solid array lines indicate the water flows and the dashed lines show the blocked water paths. The water flow is controlled by closing and opening the valves, which are represented as solid and hollow valve symbols, respectively.

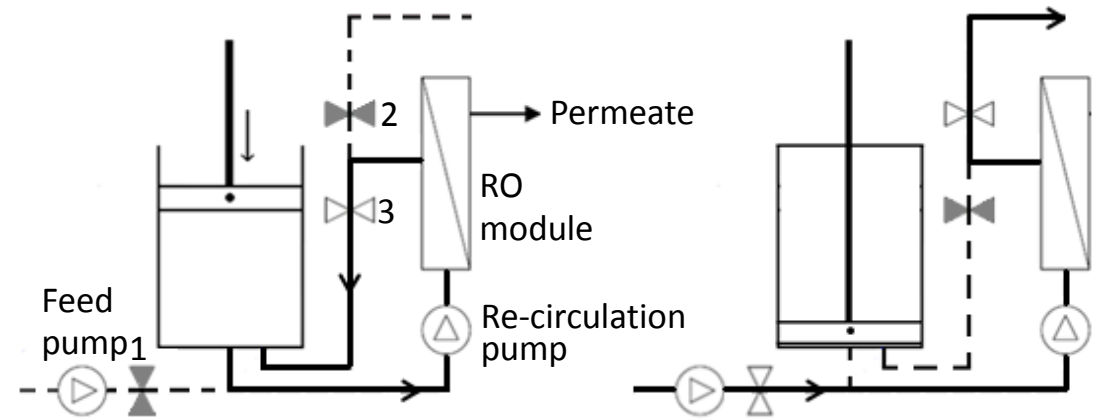

(1) Pressurisation

(2) Purging

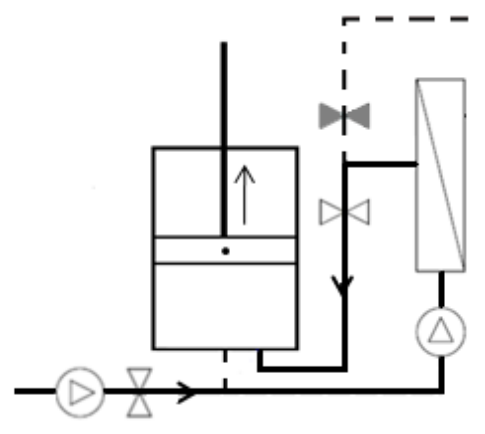

(3) Refill

\subsection{Closed Circuit Mode RO Operation}

Another BWRO desalination system that uses time-varying conditions called Closed Circuit Desalination (CCD) has been proposed and developed by Efraty [28,29]. The concept of CCD is illustrated schematically in Figure 10. Pressurized feed is supplied by a high pressure pump. A stirring device is placed inside the water vessel to prevent the concentration polarization effect. This system operates under variable pressure conditions according to the level of concentrate salinity. When it reaches the desired recovery fraction, the process stops, the container is decompressed and brine is replaced by fresh feed. Then a new batch of desalination sequence is initiated. A CCD apparatus is illustrated in Figure 11. The design includes a feed pump to provide high pressure, a circulation pump to recycle concentrate back into the RO module and valves to enable brine replacement with fresh feed when the desalination reaches a desired recovery level. In order to operate the CCD-RO continuously, a new method has been developed using multiple modules and switching among them [30]. The principle of the new apparatus is the same as the one shown in Figure 11, to which a side water vessel is added that can be either engaged with or disengaged from the CCD process by means of several actuated valves. Detailed information about continuous CCD can be found elsewhere [30]. 
Figure 10. The concept of closed circuit RO operation.

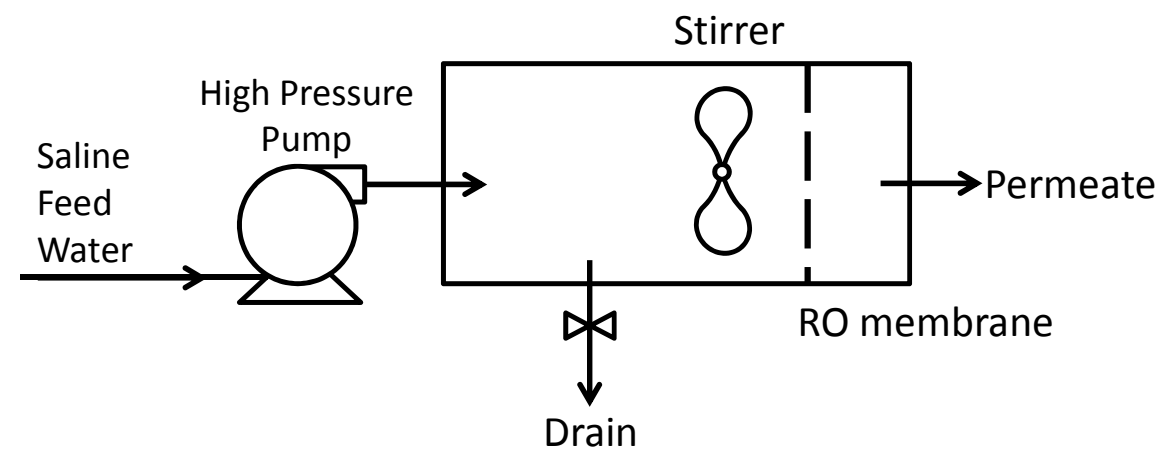

Figure 11. A schematic design of an apparatus for Closed Circuit Desalination (CCD) desalination.

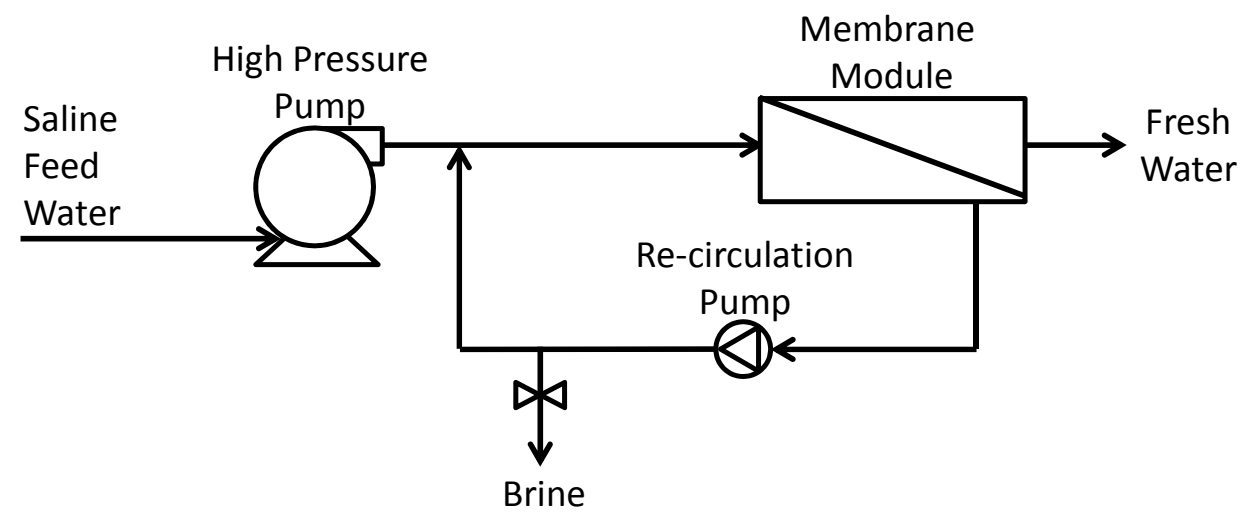

\section{Comparison of Different Configurations}

Both single and multi-stage BWRO systems have a continuous hydrodynamic process performed with fixed pressure and pressurized feed flow at every stage. For the batch mode RO and the Closed Circuit mode RO, the desalination process is performed under variable pressure conditions, because of the recycling of rejected concentrates. For DesaLink, the feed flow rate is not constant based on the steam expansion rate, which gives a varying permeate rate. At the very initial stage of pressurization, the concentration of permeate is higher than $500 \mathrm{ppm}$ (with $4000 \mathrm{ppm}$ feed) due to the low feed pressure and low flow rate. However, the pressure increases as the salinity of the recycled concentrate increases, enhancing the membrane salt rejection characteristic. Thus the permeate produced by one batch cycle has a concentration around $300 \mathrm{ppm}$. Conversely, the feed flow rate in a the CCD system is fixed, whereas the operation pressure of the feed flow is varied by means of variable frequency drive control of the high pressure pump. The high pressure pump has an average efficiency of $55 \%-60 \%$ [31]. In general, CCD has a flexible design allowing performance variations as a result of its independent control of the high pressure pump. Apart from the fixed recovery ratio that results from the fixed volume of pump volume, DesaLink can also operate on feed water with a wide range of feed BW concentrations because of the adjustable feed steam pressure and linkage mechanism. For commercial applications, DesaLink may be less attractive than the conventional BWRO systems or CCD, because desalination is preferably operated continuously. However, the purging and refill stages take only $14 \%$ of the total operation time. And simple modifications may easily solve the problem of non-continuous operation; for example, connecting two batch-RO subsystems, one at each end of the power piston. 
Moreover, since the requirements for applied pressure reach up to 7-40 bar for BW desalting, the energy consumption, due to the pumps driving the feed water into membrane module, accounts for a major portion of the total cost of water desalination. The design of DesaLink effectively eliminates the need for a high pressure pump by the linkage mechanism, which makes it more favourable for small-scale BWRO desalination than other systems with low efficiency pumps.

Table 3 summarizes expressions for determining specific energy consumption for the different RO system configurations, with the variables defined as follows: $P_{\text {osm }}$ the osmotic pressure of feed solution, $r$ is the recovery ratio, and $n$ is the number of stages. All the expressions in Table 3 are based on the following assumptions: (1) negligible salinity and pressure in the permeate, (2) negligible pressure loss in rejected concentrate, (3) linear relationship between osmotic pressure and salt concentration, and (4) 100\% efficiency of booster pump and ERD. Furthermore, the effects of concentration polarization and fouling are not considered.

Table 3. Specific energy consumption (SEC) of different BWRO system configurations.

\begin{tabular}{lll}
\hline Title & Title for this column & Title for this column \\
\hline RO system & Without energy recovery & With energy recovery \\
configuration & Specific energy consumption & Specific energy consumption \\
Single-stage & $P_{\text {osm }} \frac{1}{r(1-r)}$ & $P_{\text {osm }} \frac{1}{(1-r)}$ \\
Two-stage & $\frac{P_{\text {osm }}}{r}\left[\frac{2}{\sqrt[2]{1-r}}-(2-1)\right]$ & $\frac{P_{\text {osm }}}{r}\left(\frac{2}{\sqrt[2]{1-r}}-2\right)$ \\
$n$-stage & $\frac{P_{\text {osm }}}{r}\left[\frac{n}{\sqrt[n]{1-r}}-(n-1)\right]$ & $\frac{P_{\text {osm }}}{r}\left(\frac{n}{\sqrt[n]{1-r}}-n\right)$ \\
Batch-RO & $\quad \frac{P_{\text {osm }} \ln \frac{1}{r} \ln }{(1-r)}$ \\
CCD-RO & $P_{\text {osm }}\left[1+\frac{r}{2(1-r)}\right]$ \\
\hline
\end{tabular}

It is clear that the multi-stage RO system achieves lower SEC than its counterparts with fewer stages. To achieve the minimum energy usage, the number of serial stages should be infinite in theory, which is infeasible in practice. However, the reduction of SEC flattens out when the number of stages exceeds 4 . Figures 12 and 13 are offered to compare the performance of RO systems with different system configurations, where the normalized SEC is defined as SEC/P $P_{\text {osm }}$.

From Figure 12, for multi staged RO systems without an ERD, the theoretical limit of normalized SEC is 4, 3.6 and 3.4 for the number of stages being 1, 2, and 3, respectively. The optimum recovery ratio is around $50 \%-60 \%$. Using more stages, up to 3 , not only reduces the normalized SEC, but also improves the fractional recovery of water. However, the normalized SEC plateaus out when the number of stages is more than 3. Clearly, multi-stage RO without an ERD is not very efficient in terms of energy consumption. Conversely, as shown in Figure 13, the multi-stage RO systems with an ERD have significantly reduced the normalized SEC, with a theoretical limit of 1, when the corresponding recovery ratio approaches zero. It becomes larger when the desired fractional recovery increases. On the basis of the above analysis, it can be concluded that the normalized SEC can be reduced either by increasing the number of stages or using an ERD. It should also be noted that both methods inevitably increase the cost. 
Figure 12. Theoretical limit of normalized SEC in staged ROs without ERD.

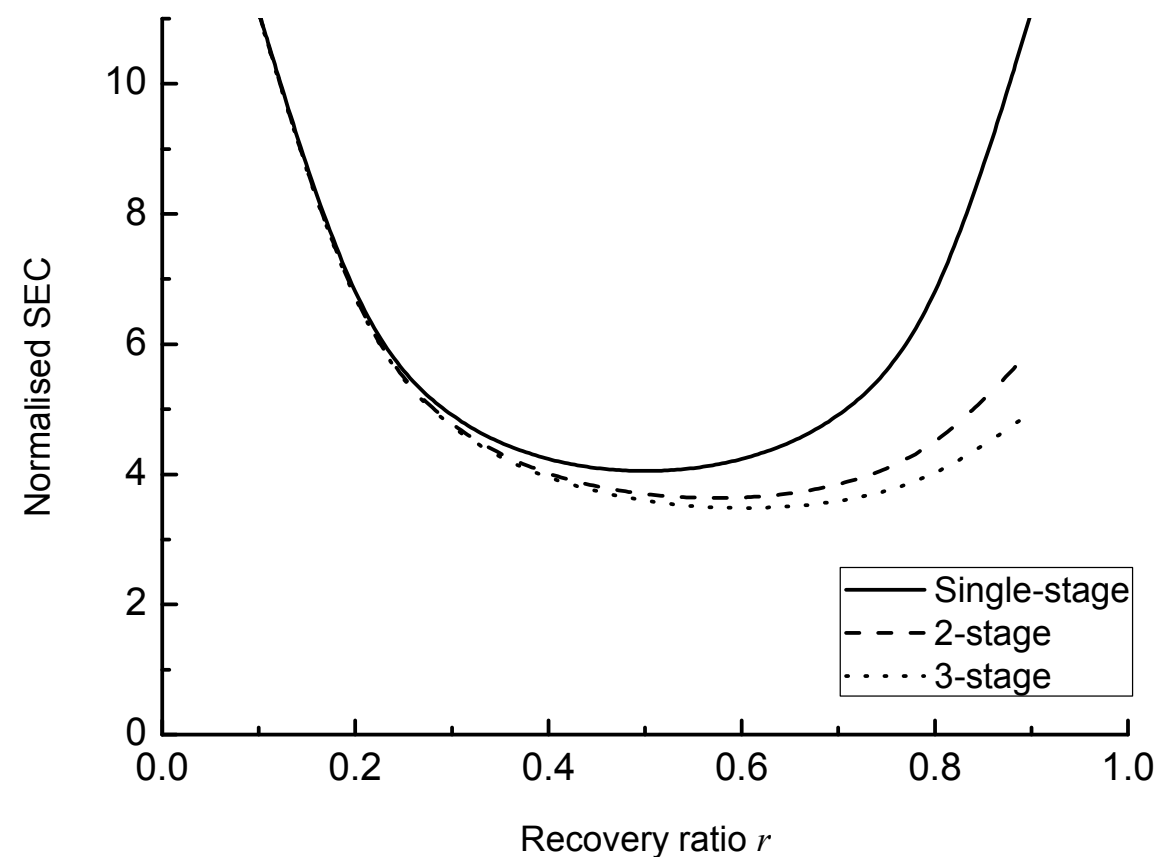

Figure 13. Theoretical limit of normalized SEC in batch-mode RO and multi-stage ROs with ERD.

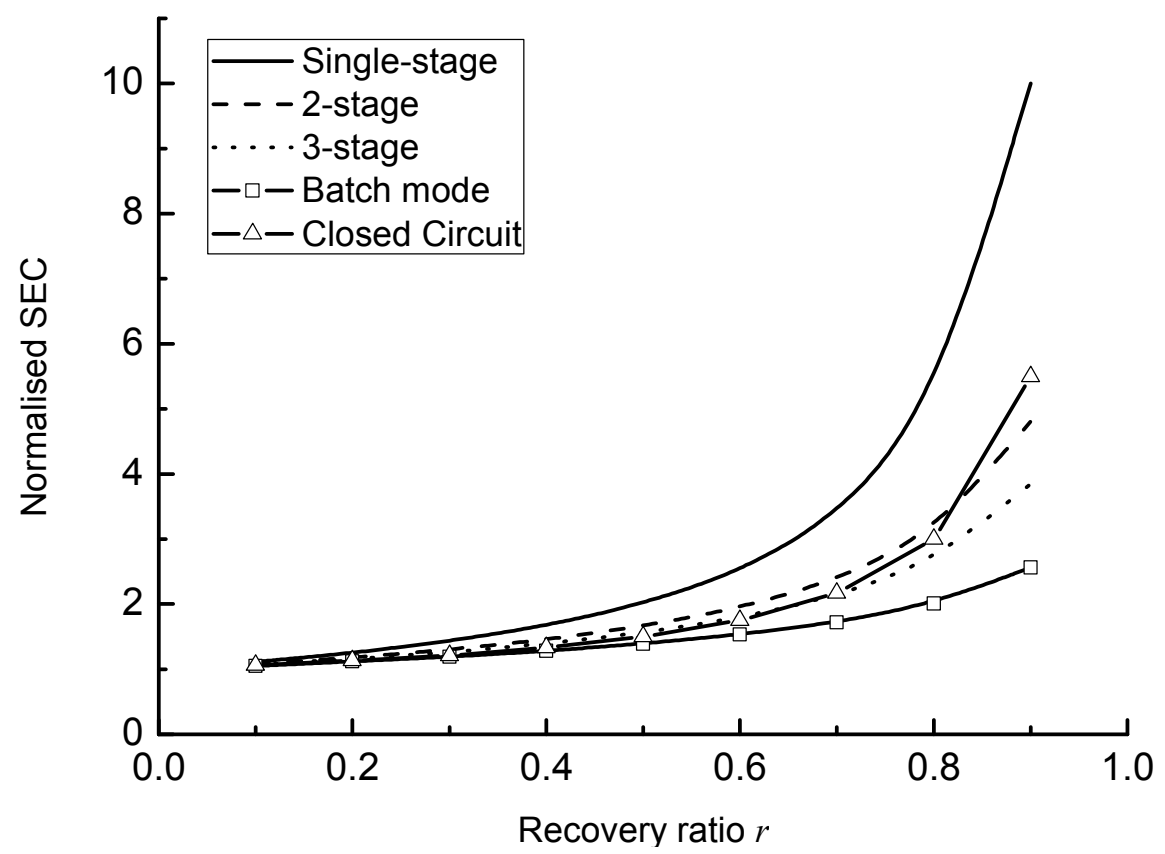

The energy consumptions of batch-RO and CCD-RO are very competitive with multi-stage systems (Figure 13). The CCD-RO system has a very similar normalized SEC to the 3-stage one, although this advantage becomes less obvious when the required recovery ratio is $80 \%$ or above. For practical facilities, it is not recommended to maintain very high recoveries based on the considerations of concentration polarization prevention and membrane fouling prevention. In particular, the batch-RO has the lowest normalized SEC due to the fixed feed water volume. The SEC of the batch-RO can be reduced by $30 \%$ compared to CCD-RO at a recovery ratio of $80 \%$. Batch mode RO operation holds promise for providing high recovery along with low energy demand and cost when compared to 
conventional systems. However, for cyclic operation, i.e., batch and CCD-RO, a question remains about the membrane stability during the repeated pressurization and de-pressurization of fluid. The operation parameters of the batch-RO system do not exceed the membrane specification provided by the manufacturer. Moreover, the loading with recycled brine and the unloading with fresh feed water can reduce the development of membrane fouling and scaling so it may even be advantageous [29].

\section{Conclusions}

In this contribution, we have discussed the critical and urgent need for BWRO systems with high productivity and low energy demand to increase water supply for various applications in remote inland areas. We have showed that brackish water composition varies widely among different locations; therefore proper analysis of water composition should be conducted prior to the BWRO plant design. We have also discussed some pre-treatment systems for RO processes and emphasized that care must be taken as the type of feed water is site-specific. Pre-treatment often involves chemical approaches to control the fouling and scaling elements in the feed water. Recently, pre-treatment processes that take advantage of membrane technology have attracted great interest due to their simplicity and effectiveness. There are a large number of BWRO plants that have been built or are under construction all over the world. With the increasing concerns of the environmental issues related to brine management in inland areas, a BWRO plant with high recovery ratio is mostly preferred. However, high production always comes hand in hand with high energy consumption. To reduce the energy demand, various designs for BWRO system have been proposed including: (1) use of additional membrane elements to recycle brine; (2) increasing the number of stages with ERD; and (3) operating the RO system in batch or CCD mode. While the multi-stage RO system with ERD can largely reduce the energy demand, the overall performance becomes less advantageous given the additional capital costs associated with the membrane elements and booster pumps. A similar improvement can be achieved by using an additional membrane on the second stage without a booster pump, thus increasing the output.

The innovative designs of both batch and CCD-RO systems are considered the most effective. The reason is twofold. First, the theoretical normalized SEC of CCD-RO is much better than for a single stage conventional system, and comparable to that of a 3-stage RO system with an ERD. The batch-RO operation can further reduce the SEC. For example, with a TDS concentration of $4000 \mathrm{ppm}$ and a target recovery of $80 \%$, a typical single-stage BWRO system without an ERD requires a theoretical energy input of $0.54 \mathrm{kWh} / \mathrm{m}^{3}$ for operation. However, to desalinate the same amount of water the CCD-RO system consumes only half of the energy, i.e., $0.26 \mathrm{kWh} / \mathrm{m}^{3}$ while only $0.17 \mathrm{kWh} / \mathrm{m}^{3}$ is needed for a batch-RO system. Both systems, therefore, are more technologically attractive thanks to their remarkable improvement over the more conventional counterparts as regards energy consumption. Second, together with their simple components and absence of costly ERD, both systems have also shown great economical advantages over the conventional systems.

The CCD-RO system powered by electrical energy has demonstrated a huge potential to be implanted on large scale to produce domestic or industrial water. On the other hand, batch-RO systems powered directly by mechanical energy, DesaLink being an example, can be more technologically feasible and commercially attractive where thermal energy is available to provide steam. We foresee 
that in the development of next generation of high recovery BWRO desalination technology, batch-RO and CCD-RO systems certainly deserve more intense research effort and may very well make remarkable contributions in the future.

\section{Appendix}

This appendix gives the derivation of theoretical SEC of Closed Circuit RO system represented in Figure 10. Assuming the initial saline water volume in the water vessel is $V_{0}$ with a concentration of $C_{0}$, and the corresponding ideal operation pressure is $P_{o s m}$. At the end of the pressurize phase, a volume of $V_{p}$ permeate is obtained. Based on the operation concept of CCD, the volume of the supplied saline water during the pressurize phase is equal to that of the obtained permeate, i.e., $V_{s}=V_{p}$, and no water is rejected during the pressurize phase. For the subsequent purge phase, a volume of $V_{0}$ fresh saline water with a concentration of $C_{0}$ is applied. Thus, the overall recovery ratio of CCD-RO is:

$$
r=\frac{V_{p}}{V_{s}+V_{0}}=\frac{V_{p}}{V_{p}+V_{0}}
$$

During the pressurize phase, the maximum concentration of the saline water $C_{\max }$ is:

$$
C_{\text {max }}=\frac{\text { Intial salt mass }+ \text { Supplied salt mass }}{\text { Volume of water vessel }}=\frac{C_{0} \cdot V_{0}+C_{0} \cdot V_{s}}{V_{0}}=C_{0} \cdot\left(1+\frac{V_{p}}{V_{0}}\right)
$$

Thus, the corresponding maximum operation pressure $P_{\max }$ is:

$$
P_{\text {max }}=P_{o s m} \cdot\left(1+\frac{V_{p}}{V_{0}}\right)
$$

The required energy is:

$$
W=\int P \cdot d v=\frac{\left(P_{o s m}+P_{\max }\right)}{2} \cdot V_{p}
$$

Substituting Equation A.3 into Equation A.4 and re-arranging the resulting expression with recovery ratio $r$ whose value is obtained from Equation A.1, the theoretical SEC of CCD-RO is:

$$
S E C=\frac{W}{V_{p}}=\frac{\left(P_{o s m}+P_{\text {max }}\right)}{2}=\frac{P_{o s m} \cdot\left(2+\frac{V_{p}}{V_{0}}\right)}{2}=P_{o s m} \cdot\left[1+\frac{r}{2 \cdot(1-r)}\right]
$$

\section{References}

1. Schwarzenbach, R.P.; Escher, B.I.; Fenner, K.; Hofstetter, T.B.; Johnson, C.A.; Von Gunten, U.; Wehrli, B. The challenge of micropollutants in aquatic systems. Science 2006, 313, 1072-1077.

2. Greenlee, L.F.; Lawler, D.F.; Freeman, B.D.; Marrot, B.; Moulin, P. Reverse osmosis desalination: Water sources, technology, and today's challenges. Water Res. 2009, 43, 2317-2348.

3. Tinker, S.; John, A.; Katherine, G. A Desalination Database for Texas; Bureau of Economic Geology, The University of Texas at Austin: Austin, TX, USA, 2005.

4. Pérez-González, A.; Urtiaga, A.M.; Ibáñez, R.; Ortiz, I. State of the art and review on the treatment technologies of water reverse osmosis concentrates. Water Res. 2012, 46, 267-283. 
5. Nicot, J.P.; Chowdhury, A.H. Disposal of brackish water concentrate into depleted oil and gas fields: A Texas study. Desalination 2005, 181, 61-74.

6. Elimelech, M.; Phillip, W.A. The future of seawater desalination: Energy, technology, and the environment. Science 2011, 333, 712-717.

7. Qiu, T.Y.; Davies, P.A. The scope to improve the efficiency of solar-powered reverse osmosis. Desalin. Water Treat. 2011, 35, 14-32.

8. Song, L.; Hu, J.; Ong, S.; Ng, W.; Elimelech, M.; Wilf, M. Performance limitation of the full-scale reverse osmosis process. J. Membr. Sci. 2003, 214, 239-244.

9. Song, L.; Hu, J.; Ong, S.; Ng, W.; Elimelech, M.; Wilf, M. Emergence of thermodynamic restriction and its implications for full-scale reverse osmosis processes. Desalination 2003, 155, 213-228.

10. Li, M. Optimal plant operation of brackish water reverse osmosis (BWRO) desalination. Desalination 2012, 293, 61-68.

11. Li, M. Reducing specific energy consumption in Reverse Osmosis (RO) water desalination: An analysis from first principles. Desalination 2011, 276, 128-135.

12. Davies, P.A. A solar-powered reverse osmosis system for high recovery of freshwater from saline groundwater. Desalination 2011, 271, 72-79.

13. Efraty, A.; Gal, Z. Closed circuit desalination series No 7: Retrofit design for improved performance of conventional BWRO system. Desalin. Water Treat. 2012, 41, 301-307.

14. Alawadhi, A.A. Pretreatment plant design-Key to a successful reverse osmosis desalination plant. Desalination 1997, 110, 1-10.

15. Vedavyasan, C. Pretreatment trends-An overview. Desalination 2007, 203, 296-299.

16. Saavedra, E.R. Graphic evolution of the 24,000 hours (3 years) operating data of a RO brackish water desalination plant, in Las Palmas, Canary Islands, Spain. Desalination 1989, 76, 15-26.

17. Schäfer, A.I.; Richards, B.S. Testing of a hybrid membrane system for groundwater desalination in an Australian national park. Desalination 2005, 183, 55-62.

18. Alghoul, M.; Poovanaesvaran, P.; Sopian, K.; Sulaiman, M. Review of brackish water reverse osmosis (BWRO) system designs. Renew. Sustain. Energ. Rev. 2009, 13, 2661-2667.

19. Rautenbach, R.; Albrecht, R. Membrane Processes; John Wiley \& Sons: Chichester, UK, 1989.

20. Sutzkover-Gutman, I.; Hasson, D. Feed water pretreatment for desalination plants. Desalination 2010, 264, 289-296.

21. Almulla, A.; Eid, M.; Côté, P.; Coburn, J. Developments in high recovery brackish water desalination plants as part of the solution to water quantity problems. Desalination 2003, 153, 237-243.

22. Nemeth, J.E. Innovative system designs to optimize performance of ultra-low pressure reverse osmosis membranes. Desalination 1998, 118, 63-71.

23. Laborde, H.; Franca, K.; Neff, H.; Lima, A. Optimization strategy for a small-scale reverse osmosis water desalination system based on solar energy. Desalination 2001, 133, 1-12.

24. Vince, F.; Marechal, F.; Aoustin, E.; Breant, P. Multi-objective optimization of RO desalination plants. Desalination 2008, 222, 96-118.

25. Lu, Y.Y.; Hu, Y.D.; Zhang, X.L.; Wu, L.Y.; Liu, Q.Z. Optimum design of reverse osmosis system under different feed concentration and product specification. J. Membr. Sci. 2007, 287, 219-229. 
26. Qiu, T.Y.; Igobo, O.N.; Davies, P.A. DesaLink: Solar Powered Desalination of Brackish Groundwater Giving High Output and High Recovery; Desalination for the Environment Clean Water and Energy: Barcelona, Spain, 2012.

27. Qiu, T.Y.; Davies, P.A. Longitudinal dispersion in spiral wound RO modules and its effect on the performance of batch mode RO operations. Desalination 2012, 288, 1-7.

28. Efraty, A. Closed circuit desalination series no-3: High recovery low energy desalination of brackish water by a new two-mode consecutive sequential method. Desalin. Water Treat. 2012, 42, 256-261.

29. Efraty, A. Closed circuit desalination series no-4: High recovery low energy desalination of brackish water by a new single stage method without any loss of brine energy. Desalin. Water Treat. 2012, 42, 262-268.

30. Efraty, A.; Barak, R.N.; Gal, Z. Closed circuit desalination series no-2: New affordable technology for sea water desalination of low energy and high flux using short modules without need of energy recovery. Desalin. Water Treat. 2012, 42, 189-196.

31. Efraty, A. Closed circuit desalination series no-6: Conventional RO compared with the conceptually different new closed circuit desalination technology. Desalin. Water Treat. 2012, 41, 279-295.

(C) 2012 by the authors; licensee MDPI, Basel, Switzerland. This article is an open access article distributed under the terms and conditions of the Creative Commons Attribution license (http://creativecommons.org/licenses/by/3.0/). 